\title{
Do Learning Styles Enhance the Academic Performance of University Students? A Case Study
}

\author{
Jorge Muñoz-Mederos $^{1}$, Elizabeth Acosta-Gonzaga ${ }^{2}$, Elena Fabiola Ruiz-Ledesma ${ }^{3}$, Aldo Ramírez-Arellano ${ }^{4}$ \\ Instituto Politécnico Nacional, UPIICSA, CDMX, México ${ }^{1,2,4}$ \\ Instituto Politécnico Nacional, ESCOM, CDMX, México ${ }^{3}$
}

\begin{abstract}
Higher education models appear to be not entirely designed to support students in facing severe challenges, such as failure in exams and dropping out of school. To solve these challenges, several models of learning styles have been proposed, under the premise that these studies contribute to improving the student's learning experience. This research aims at quantifying the impact of learning styles (learning preferences/dimensions) on students' academic performance from a higher education institution. Ninety-six undergraduate students were surveyed during the 2018-2019 school year and randomly divided into two groups: control (CG) and experimental (EG). The learning preferences of the students were identified using the Unified Learning Style Model (ULSM) instrument. Subsequently, the level of students' knowledge concerning the course was determined employing a pre-test exam. As a following step, the students of the EG consulted the learning objects designed considering different learning styles. The CG attend their lessons in a face-to-face environment; both groups answered a post-test exam to assess their learning. The learning styles' effect -learning objects were designed to cover several learning styles- on academic performance is quantified employing an ANOVA analysis. The results differ from those postulated in previous researches based on the ULSM since there is no statistical evidence that learning styles influence students' academic performance. Therefore, it is necessary to explore other cognitive and affective factors that make the student's learning experience efficient and effective.
\end{abstract}

Keywords-Learning styles; learning objects; unified learning style model (ULSM); academic performance; higher education

\section{INTRODUCTION}

According to the National Association of Universities and Institutions of Higher Education of Mexico, in the 2016-2017 school year, there were 2,655,711 students enrolled in public schools [1]. Of these students, the National Polytechnic Institute (IPN) in 2019 [2], in any of its 56 engineering and bachelor's degrees, met the demands of 108,296 students. Of these 66,139 were male students and 42,157 were female students. According to the IPN strategic management program, 13,751 students were enrolled during the 2016-2017 school year in the UPIICSA public institution [3].

However, higher education faces great challenges, and one of these problems is related to school dropout due to various factors, such as: the high failure rate that is mainly observed in subjects considered "difficult", that demand a high level of knowledge, and a lot of dedication on the part of the student. However, the educational models in public institutions do not seem to be designed entirely to help students meet this challenge.
One of the strategies to solve this challenge has been the proposal of various models of learning styles, which classify the way in which a student learns and with it, develop educational materials that serve to facilitate the learning process.

This leads the researchers to think that if students knew how they can learn better, they would notice a significant change in their learning. Moreover, most learning style models capture characteristics in the face-to-face learning context, which made it difficult to identify the learning styles of online learning students. For this reason, The Unified Learning Style Model (ULSM) [4] was proposed to unify the most relevant learning style models, and consequently, to be able to facilitate students learning in the era of web 4.0.

The identification of the way in which students learn can influence their school performance, however, this has been a matter of controversy due to the fact that there have been several studies in favor of the hypothesis that the academic performance of students is given through educational materials designed to suit learning styles, and other studies that contradict this idea.

Due to the aforementioned, this main objective of this research is to determine if the learning objects, which were designed considering the student's learning preferences, are able to impact on their academic performance compared to those students who reviewed the same topics of the learning objects, but in a face-to-face class. For this reason, the students learning style has been classified by means of the ULSM instrument and the Learning Objects (LOs) has been adapted to the detected style, then its influence on academic performance was quantified.

The design and development of personalized LOs that facilitate the retention and understanding of knowledge is considered a fundamental part of solving this problem [5].

On the other hand, there are many criticisms regarding the use of learning styles or preferences due to the fact that some learning styles or preferences are not fully compatible with the use of e-learning systems or based on teaching through the web [4]. In the same way, it warns about the risk that exists when the student is mistakenly pigeonholed in some style [6]. Additionally, most learning style models place students into mutually exclusive groups, for example, a student cannot be verbal and visual at the same time [7]. This leads to ask the question whether or not this nominal classification of having a learning preference is correct or should be considered as a gradual and not dichotomous scale. 


\section{RELATED WORKS}

Reference [8] studied the platforms that use learning styles as personalization criteria, which are also known as adaptive educational systems based on learning styles (Web-based Educational system with Learning Style Adaptation (WELSA). This study involved 64 graduate students, who were surveyed using the ULSM instrument. Each student was characterized, and adaptation rules were created according to the preferences detected by the ULSM. The results showed that the students whose learning preferences were considered to recommend the courses, achieved a favorable result in their learning, while the students who did not use the recommended course, had an adverse effect.

Similarly, the research by [9] identified the learning styles of 136 engineering students, under the premise that not all students are interested in online learning, in particular, those students belonging to the engineering areas, and that this phenomenon is related to the learning style and their perception of online learning. For this effect, the questionnaire, inventory of learning styles by [10] and the questionnaire, student perception towards online learning adapted from [11] were used. The results revealed that learning styles do not influence engineering students' perception of online learning.

The study by [12] analyzed the effects that arise when equating the teacher's learning style with the student's learning style, and thus, seek a better academic performance of the students. For this purpose, the authors used the learning styles scale of [13], which was applied to instructors and students. The results contradict what was expected; it was already desired that by matching the teacher's learning style and the student's learning style, there would be favorable effects for the students [12].

There have been studies whose objective has been showed to identify the dominant learning style of students, for example, the study directed by [14] which conducted an experiment in a high school applying a survey to 584 students in order to determine the dominant learning style based on the inventory of learning styles of [10]. The results showed that $50.5 \%$ of the students were classified as assimilators, which means that the students fluctuate between reflective observation and abstract conceptualization. Additionally, the study concludes that there is no significant difference in terms of learning style and gender, which supports the idea that the learning styles of both men and women have similar preferences.

Likewise, [5] identified the learning preferences of 58 first-year university students using the ULSM instrument. The authors also carried out evaluations on the variables, satisfaction with learning, motivation, time invested in the study, and effort while studying, and identifying the students' preferences in six key aspects: perception, processing, dependence or independence of the field, reasoning, organization and social preferences.

The results showed that after a semester in which students were made aware of their learning preferences, no significant changes were found in the variables evaluated, learning satisfaction, motivation, time spent studying or effort invested in the study. Furthermore, it is suggested to make changes in study techniques and in the way, students incorporate their learning preferences into their study habits. Finally, the authors concluded that learning preferences are a state and not a trait in students, that is, a trait is associated with stable characteristics, while states are temporary feelings or behaviors of the student at a given time.

Similarly, the study by [15] developed a management system aimed at merging LO, and the consequent adaptation to the student's learning preference. In this study 56 university students participated who were divided into two groups: control and experimental. The ULSM instrument was used to classify students according to their learning style. The proposed system searched the didactic contents for a repository of LOs and then merged LOs according to the learning preferences detected. Subsequently, the LOs fused and adapted to the students of the experimental group were shown.

The authors showed that there are favorable results for the experimental group, when by presenting the merged LOs to the students, it was possible to make the students focus on the subject of study, and avoid the distractions underlying the location of other materials that may or may not be related to their learning preference or of the study subject. A more detailed study by the same authors showed that the fusion of LOs was responsible for improving learning performance that may be related to cognitive load [16].

\section{THEORETICAL FRAMEWORK}

Learning is a process that has had an innate complexity, without showing a direct and unique solution since there are many factors that affect it, and that cannot be easily controlled [17]. Therefore, multiple ways of studying learning have been proposed, and thus, being able to propose alternatives to make more efficient results. One of the proposed alternatives is to determine the style in which a student learns.

A learning style is defined as "characteristic cognitive, affective, and psychosocial behaviors that serve as relatively stable indicators of how students perceive, interact with, and respond to the learning environment" [18]. Consequently, it is a set of ways by which a person learns as a result of various intrinsic and extrinsic factors, among which the affective and cognitive factors stand out, which may at some point influence the student's performance.

According to literature, 71 different models of learning styles can be identified, however, thirteen models have been recognized as the best results [6] and these are: Allinson's and Hayes Cognitive Style Index (CSI) by [19], Myers-Briggs Type Indicator (MBTI) by [20], Learning Style Inventory (LSI) by [21], Apter's Motivational Style Profile (MSP) by [22], Dunn and Dunn's Model by [23], Entwistle's Approaches to Studying Inventory (ASI) [24], Gregorc's Mind Styles Model and Style Delineator (GSD) [25], Herrmann Brain Dominance Instrument (HBDI) by [26], Learning Styles Questionnaire (LSQ) by [27], Learning Styles Profiler (LSP) by [28], among others. 
The huge number of models indicates that being able to identify students' learning styles is not a simple task, because each model considers some particular characteristic of their learning, leaving aside other important features. This led educational researchers to propose an instrument that could unify the cited models to identify the learning styles for each student more accurately.

\section{A. Unified Learning Styles Model (ULSM)}

The unified model of learning styles synthesizes the main characteristics of the models mentioned in literature, known as integrative taxonomy [8]. This model integrates learning preferences related to the modality of perception, form of information processing and organization, as well as social and motivational aspects.

Some of the ULSM preferences have a direct corresponding with a dimension of a learning style model, while others represent only a trait that determines a certain style [8].

One of the corresponding dimensions is field dependence or independence, which was based on the learning styles model of [29], including the name and the definition. The opposite case can be observed in the preference regarding attention to details, since it does not have direct correspondence with any of the dimensions of the existing learning styles models [8].

The ULSM includes the following dimensions and preferences: Perception modality and its preferences: visual vs verbal; Information processing and its preferences: abstract vs concrete, serial vs holistic; Experimentation and its preferences: active vs reflective observation, careful vs not careful with details; Field and its preferences: dependency / independence; Reasoning and its preferences: deductive vs inductive; Organization of the information and its preferences: synthesis vs analysis; Motivation and its preferences: intrinsic vs extrinsic, deep vs superficial vs strategic vs resistant approach; Persistence and its preferences: high vs low; Pace and its preferences: focus on one task at a time vs alternating tasks and topics; Social aspects and its preferences: individual work vs team work, introversion vs extroversion, competitive vs collaborative; Coordinating body and its preferences: affectivity vs thought.

The preferences of the perception modality dimension are included from several models of traditional learning styles such as: the Felder-Silverman Learning Style Model (FSLSM) (visual vs verbal dimension) [30], VARK (Visual, Aural, Reading/writing, Kinesthetic) [31], VAK (Visual, Auditory, Kinesthetic), of the Dunn and Dunn model [23] (visual, auditory, kinesthetic, tactile) and of the Riding model (verbalizer / image generator) [32]. Moreover, only visual vs. verbal preference was considered, because kinesthetic or tactile preference is difficult to perceive in an online environment [8]. One of the characteristics that was preserved to identify this dimension was the definition of the FelderSilverman Learning Style model (FSLSM) which says: "visual students remember better what they see (images, diagrams, graphs, etc.), on the other hand, verbal students rely more on either spoken or written words” [8].
The information processing dimension includes preferences: concepts and generalizations, abstract vs. concrete, practical examples. These preferences were based on Kolb's learning cycle (abstract conceptualization vs concrete experimentation) [21] and Gregorc's model (abstract vs concrete) [25].

The serial vs. holistic preference was inspired by the FSLSM (sequential or global) [30] and by Pask's model (serial or holistic) [33].

From Kolb's learning cycle, the preference of active experimentation vs. reflective observation was taken, which is also described in the FSLSM (active or reflective) [30] and in the Honey and Mumford model (activist or reflector) [27].

According to [8], students who have abstract preference tend to trust contextual interpretation, while students who demonstrate concrete preference rely on immediate experience to capture learning. Similarly, students with a sequential preference tend to understand knowledge linearly, while students who have a global learning preference tend to learn in disorder. Some consider that they perform their learning in large leaps, and that they have the ability to make fast connections between different topics.

The field-dependent vs. field-independent dimension has been based on the model of [29]. This dimension refers to the student's environment and how the environment affects or does not affect their interpretation and the ability to locate information. The meaning is that students who depend on the field have difficulty locating the precise information they need. If this information is hidden or if there is other information superimposed that prevents it from being easily accessible, so they are more oriented towards people. On the other hand, students classified as independent of the field find it easier to recognize and select what is important in their environment, with a kind of abstraction and additionally have an impersonal orientation [8].

The reasoning dimension and its inductive vs. deductive preferences were taken from the first version of the FSLSM. Inductive students prefer to reason from particular facts or situations, and thus, be able to reach a general conclusion. That is, they go from the specific to the general. They also respond better to problem-based learning (fictional or real), as well as inquiry learning. Deductive students prefer to reason from the general to the specific, which is why they prefer the course to begin with the theoretical foundations and with the basic principles and then continue with the applications corresponding to the course [8].

The information organization dimension and its preferences, synthesis vs analysis, had no basis in any previous learning style model. Similar concepts can be found in the Allinson and Hayes model (intuitive or analytical) [19] and in the Riding model (holistic or analytical). A student with a preference for synthesis is the one who has a general image of the topic and who tends to combine different elements to understand something completely. Furthermore, a student with a preference for analysis focuses on each of the parts of a whole, as well as on the basic principles, and therefore be able to build what remains [8]. 
The motivation dimension and the deep vs. strategic vs. superficial vs. reticent preferences was based on the Entwistle model [24]. From the Grasha-Riechmann model the reticent preference was taken which is similar to the GrashaRiechmann avoidance concept [34].

The intrinsic vs extrinsic preference does not have a direct correspondence with a learning style model, but it is related to the Entwistle model, as well as the telic (serious) and paratelic (playful) dimensions of [22].

According to [8], the preferences of the motivation dimension have the following characteristics: students with the preference of profound are oriented towards meaning. They try to understand ideas by themselves or by their own means. They generally show interest in the full content of the course. Students with a preference for strategic focus, tend to be achievement-oriented; generally, in a group of students they are the ones who want to obtain the highest grades and they are constantly attentive to the requirements and evaluation criteria. Likewise, they try to guide the work to perceived preferences in teachers.

Students with a superficial preference are oriented towards reproduction, that is, their intention is to pass the different evaluations that are presented to them, by memorizing facts, data and whatever else they need. They generally do not find meaning in the new ideas that are presented to them; they tend not to reflect on the purpose or strategy of a certain action, and they feel excessive pressure as they worry about the work.

Students with the resistant preference show a total disinterest in the course and generally refuse to participate in the learning activities suggested by the teacher. Most of the time they are apathetic students; they do not pay attention to their classes and they are disobedient. Students who are intrinsically motivated learn by the mere fact that their attention will generate a new experience in their life, while those who are extrinsically motivated learn to obtain an external reward which serves as motivation itself [8].

For the persistence dimension, its preferences were based on the Dunn and Dunn model [23] (persistent or nonpersistent). In this dimension, students who demonstrate a high persistence preference are those students who are inclined to complete all the tasks that are entrusted to them, sometimes regardless of the cost. They tend to spend a lot of time studying and sometimes, if necessary, they review the study material over and over again. Students who have a low persistence preference tend to take consecutive breaks and rarely return to study material [8].

The pacing dimension includes two preferences, concentrating on one task at a time or alternating between multiple tasks and topics. This dimension was not based on any previous learning style model. Students who demonstrate a preference to concentrate on one task at a time are considered as having linear learning. This means that they will not continue with the learning if they do not complete the current task. Sometimes, they have few changes, or they have no changes and jumps of activity. Students who have the preference to alternate subjects or topics are considered to a certain extent inconstant because they jump from topic to topic and from subject to subject and this includes jumps from one course to another [8].

The social aspects dimension and their preference to learn alone vs. learning among peers, has been based on the Dunn and Dunn model, and has also been related to other learning styles such as the active or reflective of the FSLSM.

Introversion vs. extraversion preference was based on the Myers-Briggs classification (MBTI). From the Grasha and Riechman-Hruska model [13], the competitive vs. collaborative preferences were taken, which is also related to the autistic domain preference of [22].

Students who have a preference for introversion are those students who tend to avoid social contact and are constantly preoccupied with their thoughts and inner feelings. Extroverted students are constantly involved with social and practical realities of that same nature, instead of worrying about their thoughts and feelings [8]. Students who demonstrate a competitive preference tend to participate in any activity as long as they have competition with someone else. While students who have a preference for collaboration, feel better helping a common goal for all, constantly considering the "win-win" [8].

The coordinating instance dimension of the learning process and its affectivity vs. thought preferences is related to the feeling vs. thought preferences of the Myers-Briggs model (MBTI). Students who demonstrate a preference for affectivity tend to complete tasks based on intuition and their way of feeling, while those students who have a preference for learning thinking, make decisions based on analysis, logic, and reasoning [8].

As mentioned above, the ULSM has only integrated learning style preferences related to the web-based educational context, rather than the context for face-to-face learning. Accordingly, only those preferences related to the context of education 4.0 have been included.

Educational environments for education 4.0 have been enriched by the incorporation of Learning Objects (LOs), which are defined as a set of educational experiences obtained through reflection and experimentation in practice aimed at solving real educational problems, and that are represented in Multimedia Teaching Materials (MTM), in order to avoid memorization of information [35]. LOs are all those digital or non-digital entities that can be reused or referenced during learning with technological support [36]. For this research LOs have been considered as the set of reusable or not reusable multimedia educational materials, and that are intended to facilitate learning for students.

Currently, LOs are used in interactive learning environments, distance learning systems, and collaborative learning environments; and are required by multiple companies to offer online training, such as Oracle company that offers its training courses virtually through what is known as Oracle University, which uses learning objects (texts, videos, illustrations, etc.) to facilitate the learning of the personnel concerned. 


\section{METHOD}

The study was carried out in a public higher education school with 96 students who had enrolled on the web technologies course of the Industrial Administration career of 2019 scholar year. The age of the students ranged from 20 to 23 years old. It was explained to teachers and students of six groups the objective of the investigation. They both agreed to participate. In each class, the students' total number was randomly divided into two groups: the Control Group (CG) and the Experimental Group (EG).

LOs were designed and developed, including the following dimensions of the ULSM and its respective preferences (learning styles), perception, information processing, field independence, reasoning and organization. The LOs were upload to Moodle platform to be available for the students.

The ULSM instrument was employed to gather the students' preferences. It has been validated through the electronic learning platform, WELSA [8]. Each student's prior knowledge about the course was determined by an evaluation (pre-test) related to the course topic. No statistical difference was found; the details are presented next.

The GC students took all their classes in person, attending their classroom with their teacher. The GE students attended the computer room to take all their course classes using the Moodle platform.

Then, a post-evaluation (post-test) was administrated to the students. This evaluation was carried out to determine the knowledge acquired from the face-to-face or online lessons. The GC students carried out their evaluation on paper, and the EG students through the platform. The questions on both tests were the same. The normality and homoscedasticity of both pre-test and post-test were evaluated. Then, two-way ANOVA (group $\mathrm{x}$ dimension) were performed to determine the effect of the dimensions of the ULMS on the students' performance in both groups (CG, EG).

\section{REsUlts}

The dominant learning style of each student was determined through the ULSM instrument. The results are shown in Table 1.

TABLE I. StUdents’ LEARNing STYLE ACCORDING to ULMS DIMENSIONS

\begin{tabular}{|l|l|}
\hline Perception dimension & \\
\hline Kinesthetic & $65 \%$ \\
\hline Aural & $21 \%$ \\
\hline Visual & $6 \%$ \\
\hline Reading/writing & $8 \%$ \\
\hline Information processing dimension & \\
\hline Concrete & $86 \%$ \\
\hline Abstract & $14 \%$ \\
\hline Holistic & $64 \%$ \\
\hline Sequential & $36 \%$ \\
\hline Active & $50 \%$ \\
\hline Reflective & $50 \%$ \\
\hline
\end{tabular}

\begin{tabular}{|l|l|}
\hline Field dimension & \\
\hline Dependent & $33 \%$ \\
\hline Independence & $67 \%$ \\
\hline Reasoning dimension & \\
\hline Deductive & $26 \%$ \\
\hline Inductive & $74 \%$ \\
\hline Information dimension & \\
\hline Synthesis & $66 \%$ \\
\hline Analyze & $32 \%$ \\
\hline Motivation dimension & \\
\hline Deep & $44 \%$ \\
\hline Superficial & $31 \%$ \\
\hline Strategic & $21 \%$ \\
\hline Disinterest & $4 \%$ \\
\hline Persistence dimension & \\
\hline High persistence & $51 \%$ \\
\hline Low persistence & $49 \%$ \\
\hline Pacing dimension & \\
\hline Completed one task & $70 \%$ \\
\hline Jumped between tasks & $30 \%$ \\
\hline Social dimension & \\
\hline Work in a team & $25 \%$ \\
\hline To do it individually & $75 \%$ \\
\hline Collaborative & $84 \%$ \\
\hline Competitive & $16 \%$ \\
\hline Extrovert & $48 \%$ \\
\hline Introvert & $52 \%$ \\
\hline & \\
\hline
\end{tabular}

A. Influence of Learning Styles on Students Performance

The Shapiro-Wilk test showed that the grade obtained in the pre-test of the CG y GE has normal distribution, see Table 2.

TABLE II. The Shapiro-WILK TEST FOR Pre-Test EVAluation

\begin{tabular}{|l|l|l|l|}
\hline \multicolumn{5}{|l|}{ Pre-test } & Statistic & df & Sig \\
\hline & 0.972 & 43 & 0.376 \\
\hline CG & 0.975 & 53 & 0.326 \\
\hline EC & \multicolumn{3}{|c|}{$\quad(p=0.05)$}
\end{tabular}

Levene's test showed that the grade of the pre-test is homoscedastic, $F(94)=0.576, p=0.450$.

The student's t-test showed no difference between the grade of pre-test of EG students and CG students, see Table 3.

Thus, the students in both groups have the same level of prior knowledge.

TABLE III. STUDENT T-TEST OF THE GRADE FOR THE PRE-TEST EVALUATION

\begin{tabular}{|c|c|c|c|c|c|}
\hline \multicolumn{6}{|c|}{ Pre-test } \\
\hline & $\mathrm{M}$ & DS & t-value & $\mathrm{df}$ & p-value \\
\hline CG & 6.638 & 1.1479 & \multirow{2}{*}{-1.18} & \multirow{2}{*}{94} & \multirow{2}{*}{0.241} \\
\hline EC & 6.337 & 1.3553 & & & \\
\hline
\end{tabular}


The post-test evaluation showed that the data are normal, this is shown in Table 4.

TABLE IV. THE SHAPIRO-WILK TEST FOR POST-TEST EVALUATION

\begin{tabular}{|l|l|l|l|}
\hline \multicolumn{5}{|l|}{ Post-test } & Statistic & df & Sig \\
\hline & 0.953 & 43 & 0.074 \\
\hline EC & 0.976 & 53 & 0.347 \\
\hline
\end{tabular}
.057 .

Also, the grade was homoscedastic, $F(94)=3.721, p=$

The student's t-test shown that the students who used the LOs (EG) and those who attended the lesson face to face (CG) have not statistical difference in post-evaluation, see Table 5.

TABLE V. Student T-Test of the Grade for the Post-Test EVALUATION

\begin{tabular}{|l|l|l|l|l|l|}
\hline \multicolumn{5}{|l|}{ Post-test } \\
\hline & M & DS & t-value & df & p-value \\
\hline CG & 7.2563 & 1.4840 & \multirow{2}{*}{-1.156} & 94 & 0.25 \\
\hline EC & 7.5447 & 1.2148 & & & \\
\hline
\end{tabular}

Therefore, both groups had the same level of knowledge after reviewing the LOs or attending face-to-face lessons. Thus, the LOs designed based on several learning styles of the ULSM do not influence academic performance.

\section{B. Influence of the Dimensions of Learning Styles on Students Performance}

A two-way ANOVA test (group x preference) were carried out to analyze each dimension of the students' learning styles in their performance. The ANOVA showed no significant difference between the interaction of the LOs and preferences: kinesthetic, visual, aural, reading/writing, $F(2.89)=1.293, p$ $=.279$. Thus, the students with kinesthetic, visual, aural and reading/writing preferences obtained the same performance by consulting the LOs or attending the teacher's lecture.

Likewise, the results have shown no significant difference between the interaction of the LOs and the information processing dimension (abstract vs concrete), $F(1.92)=.254, p$ $=.615$. Therefore, students with abstract, concrete preferences obtained the same performance by consulting the LOs or attending class with the teacher. Also, no statistically significant difference has been found between the interaction of the LOs and the information processing dimension (active vs reflective), $F(1.92)=1.548, p=.217$. Consequently, students from both groups with active or reflective preferences obtained the same performance. The statistical analysis indicated no difference between the interaction of LOs and the information processing dimension (sequential vs global), $F$ $(1.92)=2.006, p=.160$. Therefore, students with sequential or global preferences obtained the same grade.

Furthermore, no statistically difference between the interaction of the LOs and the field dependence dimension (dependent or independent), $\mathrm{F}(1.92)=.047, \mathrm{p}=.829$ was found. A similar result was realized for deductive or inductive learning, $F(1.92)=.166, p=.685$, for synthesis vs analysis, $F$ $(1.92)=.455, p=.502$; and for individual vs team, $F(1.92)=$ $1.787, p=.185$.

\section{DISCUSSION}

The results have shown that there is no evidence that the individual learning styles and the dimensions of the ULSM influence students' academic performance. Therefore, there was no statistical difference between face-to-face and blended learning which shows that blended learning can be just as effective as face-to-face learning. This is certainly a good choice to meet a challenge of the growing student population demanding quality education [37].

A previous study [14], whose objective was to identify the dominant learning style of students, shows that the majority of students are kinesthetic (65\%), with inductive reasoning (74\%), with a preference for synthesis (66\%), deeply motivated (44\%), highly persistent (51\%), and who prefer to work individually (75\%).

The study of [8] showed that the courses recommended based on students learning styles improve academic achievements. In contrast, our results show that learning styles —included in the LOs — do not affect the students learning performance.

Our results agree with those found in [9], who showed that learning styles do not influence students' perception of online learning. It is also consistent with the study [5], which found no significant difference in learning satisfaction changes, motivation, time spent studying, and effort invested in the study after considering the students' learning preferences. Thus, a learning preference is a state-temporary feelings or behaviors - and not a trait —associated with stable characteristics - in students [5].

\section{CONCLUSIONS}

In conclusion, research supports the conjecture that learning styles positively influence students' academic performance. On the other hand, our results argue that student performance does not depend on learning style. Consequently, for future work, it is necessary to explore other psychological, affective, and cognitive factors that could influence the students' learning performance to depict "the big picture" and develop strategies to mitigate their negative impact. In developing countries, online learning can be a solution for many aspirants that are not admitted to public universities in a face-to-face career. However, this strategy will be successful if the challenges such as the failure in exams and the high rate of students drop out are solved.

\section{ACKNOWLEDGMENT}

This work was supported by Instituto Politécnico Nacional [grant numbers SIP20201101, SIP20200832].

\section{REFERENCES}

[1] ANUIES, “Anuarios Estadísticos de Educación Superior”, Información Estadística de Educación Superior, 2019. [Online]. Available at: http://www.anuies.mx/informacion-y-servicios/informacion-estadisticade-educacion-superior/anuario-estadistico-de-educacion-superior. [Consulted: 27-feb-2020].

[2] IPN, “Agenda Estadística. Enero-Diciembre 2018”, 2018. 
[3] IPN, “Estadística Básica. Inicio de periodo escolar 2018-2019/1 y Fin de periodo escolar 2018-2019/2”, 2019.

[4] E. Popescu, "Diagnosing students' learning style in an educational hypermedia system”, Cogn. Emot. Process. Web-Based Educ. Integr. Hum. Factors Pers., pp. 187-208, 2009.

[5] C. A. Giuliano, L. R. Moser, V. Poremba, J. Jones, E. T. Martin, y R. L. Slaughter, "Use of a unified learning style model in pharmacy curricula”, Curr. Pharm. Teach. Learn., vol. 6, núm. 1, pp. 41-57, 2014.

[6] F. Coffield, D. Moseley, E. Hall, y K. Ecclestone, Learning styles and pedagogy in post-16 learning. A systematic and critical review, Primera., núm. January. Londres: Learning and Skills Research Centre, 2004.

[7] P. A. Kirschner, “Stop propagating the learning styles myth”, Comput. Educ., vol. 106, pp. 166-171, 2017.

[8] E. Popescu, "A unified learning style model for technologyenhanced learning: What, why and how?”, Int. J. Distance Educ. Technol., vol. 8, núm. 3, pp. 65-81, 2010.

[9] M. S. A. Mansor y A. Ismail, "Learning Styles and Perception of Engineering Students Towards Online Learning”, Procedia - Soc. Behav. Sci., vol. 69, núm. Iceepsy, pp. 669-674, 2012.

[10] D. Kolb, "The Process of Experiential Learning”, en Experiential Learning: Experience As The Source Of Learning And Development, New Jersey: Prentice Hall, Inc., 1984, pp. 20-38.

[11] J. O’Malley y H. McCraw, "Students Perceptions of Distance Learning, Online Learning and the Traditional Classroom", Online J. Distance Learn. Adm., vol. 2, núm. 4, pp. 1-10, 1999.

[12] S. Dinçol, S. Temel, Ö. Ö. Oskay, Ü. I. Erdoğan, y A. Yilmaz, "The effect of matching learning styles with teaching styles on success", Procedia - Soc. Behav. Sci., vol. 15, pp. 854-858, 2011.

[13] A. Grasha y S. Riechman-Hruska, "Teaching style survey (Encuesta de estilos de enseñanza)”, Teaching style survey, 1996. [En línea]. Disponible en: http://www.longleaf.net/teachingstyle.html. [Consultado: 28-feb-2019].

[14] Ö. Karakiş, "Dominant Learning Styles of Preparatory Class Students", Procedia - Soc. Behav. Sci., vol. 55, pp. 1079-1088, 2012.

[15] A. Ramírez-Arellano, J. Bory-Reyes, y L. M. Hernández-Simón, "Learning Object Assembly Based on Learning Styles", en Smart Education and e-Learning 2016, 2016, vol. 59, pp. 447-462.

[16] A. Ramírez-Arellano, J. Bory-Reyes, y L. M. Hernández-Simón, Learning Object Retrieval and Aggregation Based on Learning Styles, vol. 55, núm. 6. 2016.

[17] E. Brown, T. Fisher, y T. Brailsford, "Real users, real results: Examining the limitations of learning styles within AEH", Hypertext 2007 Proc. Eighteenth ACM Conf. Hypertext Hypermedia, HT’07, pp. 57-66, 2007.

[18] F. Romanelli, E. Bird, y M. Ryan, "Learning styles: A review of theory, application, and best practices”, Am. J. Pharm. Educ., vol. 73, núm. 1, 2009.

[19] C. W. Allinson y J. Hayes, "The cognitive style index: A measure of intuition-analysis for organizational research”, J. Manag. Stud., vol. 33, núm. 1, pp. 119-135, 1996.

[20] I. Briggs-Myers, M. McCaulley, N. Quenk, y A. Hammer, MBTI Manual. A Guide to the Development and Use of the Myers-Briggs
Type Indicator, Tercera. Palo Alto, California: Consulting Psychologists Press, Inc., 1993.

[21] A. Kolb y D. Kolb, "The Kolb Learning Style Inventory—Version 3.1 2005 Technical Specifi cations”, HayGroup, núm. January 2005, 2015.

[22] M. J. Apter, Motivational Styles in Everyday Life. Aguide to Reversal Theory, Primera. American Psychological Association, 2001.

[23] R. Dunn y S. Griggs, Synthesis of the Dunn and Dunn learning-style model research: Who, what, when, where, and so what? St. John's University Press, 2007.

[24] N. Entwistle, "Improving Teaching through Research on Student Learning”, en University teaching: International perspectives, Primera., J. Forest, Ed. Garland Publishing, Inc, 1998, pp. 73-112.

[25] A. F. Gregorc, Gregorc Style Delineator: A Self-assessment Instrument for Adults, 3a ed. Gregorc Associate, 2006, 1985.

[26] N. Herrmann, The Whole Brain business book: Unlocking the power of whole brain thinking in organizations, teams, and individuals. McGraw Hill, 1996.

[27] P. Honey y A. Mumford, The Learning Styles Helper's Guide. Maidenhead, UK: Peter Honey Publications (2000), 2000.

[28] C. Jackson, Manual of the Learning Styles Profiler. Sydney: Cymeon Research, 2002.

[29] H. A. Witkin, R. B. Dyk, H. F. Fattuson, D. R. Goodenough, y S. A. Karp, Psychological differentiation: Studies of development. Oxford, England: Wiley, 1962.

[30] R. Felder y L. Silverman, "Learning and teaching styles in engineering education”, Eng. Educ., vol. 78, núm. 7, pp. 674-681, 1988.

[31] N. Fleming, "I'm different; not dumb. Modes of presentation (V.A.R.K.) in the tertiary classroom", en Research and Development in Higher Education, Proceedings of the 1995 Annual Conference of the Higher Education and Research Development Society of Australasia (HERDSA), 1995, pp. 308-313.

[32] R. Riding y S. Rayner, Cognitive Styles and Learning Strategies. Understanding Style Differences in Learning and Behaviour, Novena. New York: Routledge. Taylor \& Francis Group, 2007.

[33] G. Pask, "Learning Strategies, teaching strategies, and conceptual or learning style”, en Learning Strategies and Learning Styles, R. R. Schmeck, Ed. New York: Plenum Press, 1988, pp. 83-100.

[34] A. Grasha, "Teaching with Style: The integration of teaching and learning styles in the classroom.”, Prof. Organ. Dev. Netw. High. Educ., vol. 7, núm. 5, 1995.

[35] S. Horton, Web Teaching Guide: A Practical Approach to Creating Course Web Sites, Primera. Yale University Press, 2000.

[36] IEEE Learning Technology Standards Committee, "The Learning Object Metadata standard”, Working groups and study groups, 2007. [En línea]. Disponible en: https://www.ieeeltsc.org/workinggroups/wg12LOM/lomDescription/. [Consulted: 29-feb-2020].

[37] La Jornada, "Entre 2000 y 2021, la matrícula de educación superior creció 2 millones", 2021. [On line]. Available at: https://www.jornada.com.mx/notas/2021/03/17/sociedad/entre-2000-y2021-la-matricula-de-educacion-superior-crecio-2-millones/ [Consulted: 27-jun-2021]. 